\title{
Электромагнитные воздействия на жидкий и кристаллизующийся металл при непрерывной разливке стали: перспективы использования мирового опыта и отечественных разработок
}

\author{
${ }^{1}$ В.И. Дубоделов, ${ }^{1}$ А.Н.Смирнов, ${ }^{2}$ А.Ф. Колесниченко \\ 1 - Физико-технологический институт металлов и сплавов, г. Киев, Украина \\ 2 - ООО «Нет Шейп Каст Украина», г. Мариуполь, Украина
}

Проанализировано применение электромагнитных полей в непрерывной разливке стали в мире и показаны основные разновидности электромагнитных устройств. Представлены основные технологические схемы использования электромагнитных полей в МНЛЗ, а также проведено описание физических эффектов, которые при этом проявляются. Проведен подробный анализ влияния данных физических эффектов на повышение качества непрерывнолитых заготовок и производительности МНЛЗ.

Ключевые слова: непрерывная разливка стали, электромагнитное перемешивание, промежуточный ковш, кристаллизатор, зона вторичного охлаждения.

Непрерывная разливка стали на сегодня является основным металлургическим переделом, обеспечивающим получение широкой номенклатуры стального полуфабриката для различных отраслей промышленности [1]. При этом, наряду с постоянно существующими требованиями повышения производительности и улучшения качества продукции, сегодня на первый план выходит обеспечение ресурсосбережения и экологическая безопасность производства. Поэтому для производства литых металлических заготовок является весьма актуальным поиск новых решений, могущих создать предпосылки для повышения качества продукции и роста технико-экономических показателей процесса.

Одним из таких решений стало использование электромагнитных полей [2]. Научные и технологические разработки в этой области применительно к процессам непрерывной разливки стали проводятся с 70-х гг. прошлого века. В 80-х гг. были получены существенные положительные 
результаты - в частности, были созданы электромагнитные устройства для торможения потоков стали и стабилизации уровня расплава в кристаллизаторах МНЛ3, а также электромагнитные перемешиватели жидкого металла в различных зонах затвердевания заготовки. Такой научно-технологический прорыв стал возможен благодаря развитию представлений о механизме кристаллизации непрерывнолитых заготовок в условиях воздействия на фронт кристаллизации принудительных потоков [3], a также благодаря разработке нового поколения электротехнического оборудования на соответствующей элементной базе, новых составов огнеупорных материалов, имеющих высокую термическую, химическую и механическую стойкость. В результате, рост требований к качеству продукции и развитие эффективных методов и средств электромагнитной обработки расплавов привели к тому, что в международные стандарты были внесены положения об обязательном использовании электромагнитных воздействий (в частности, перемешивания на МНЛЗ) при производстве определенных марок высококачественных сталей.

На сегодня в мировой практике непрерывной разливки стали применение электромагнитных воздействий является хорошо известным $[2,4]$. Так, на международных конференциях по электромагнитной обработке материалов доклады и презентации, посвященные использованию электромагнитных полей в технологиях непрерывной разливки стали, выделяются в отдельную секцию ввиду большого количества разнообразных исследований в данной области, оригинальности заложенных научных идей и примененных технических решений, а также особого статуса непрерывной разливки в современном производстве металлопродукции.

На сегодня известен опыт применения электромагнитных полей на различных стадиях металлургического передела стали в непрерывнолитую заготовку после выдачи расплава из плавильного агрегата (конвертер или электропечь) в агрегат «ковш - печь» (рис. 1). 


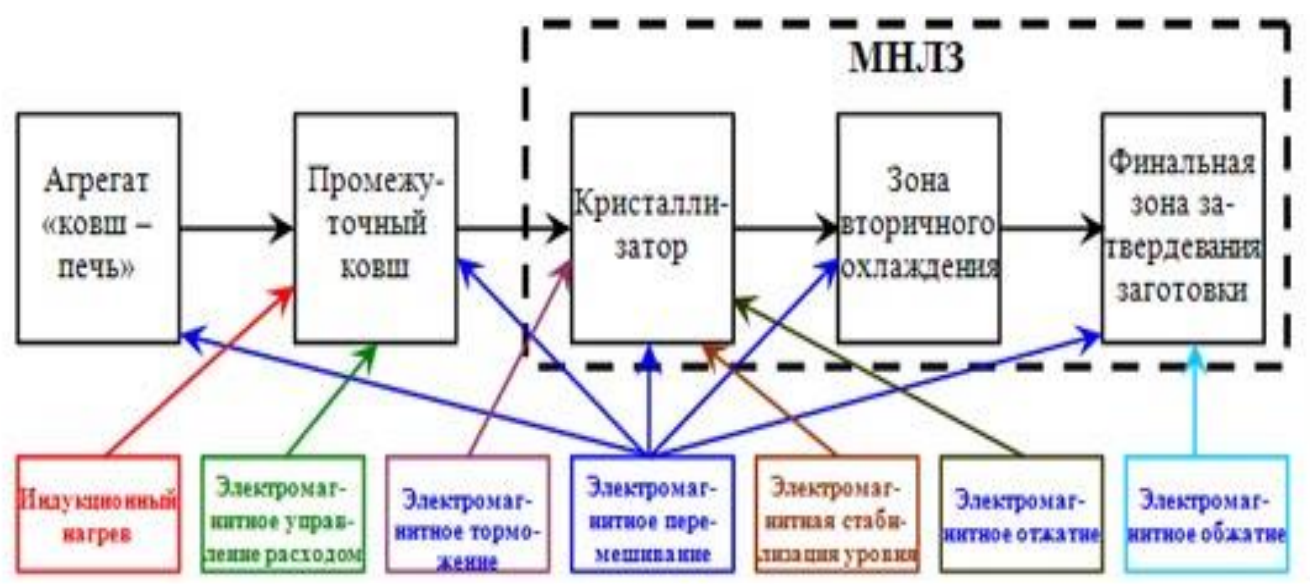

Рис. 1. Применение электромагнитных воздействий на различных стадиях процесса непрерывной разливки стали

\section{Электромагнитное перемешивание стали в агрегате «ковш - печь»}

После выпуска стали из плавильного агрегата, eе внепечную обработку (рафинирование от газовых и неметаллических включений, доводку по температуре и химическому составу) проводят в агрегатах «ковш - печь», которые, как правило, оснащаются дополнительными устройствами для нагрева, вакуумирования, продувки инертным газом, а также перемешивания [1]. Изначально для этой цели использовали энергию газовых струй, однако было доказано, что электромагнитное перемешивание является технологически более эффективным и экономически выгодным [5]. Так, газовое перемешивание, несмотря на простоту реализации и сообщение расплаву высокой удельной энергии, имеет ряд неблагоприятных особенностей: - симметрирование потоков относительно места ввода газа в жидкий металл, что способствует быстрому образованию застойных зон; - интенсивная турбулизация расплава вблизи зоны ввода газовой среды и слабая - в других зонах; - необходимость применения специальных устройств, контактирующих с перегретым расплавом, и механизмов их перемещения.

Напротив, устройства для электромагнитного перемешивания жидкой стали бегущим магнитным полем [5], устанавливаемые, как правило, на боковых стенках агрегатов «ковш - печь», лишены подобных недостатков, обеспечивая не только бесконтактное выделение значительной электромагнитной 
мощности непосредственно в объеме расплава, но и широкие возможности по организации разнообразных режимов движения расплава и создание необходимых условий для его равномерного перемешивания по высоте агрегата, ускорения скачивания шлака с поверхности ванны, управляемого нарушения шлакового покрова (открытие так называемого «шлакового окна» с целью ввода добавок и его закрытие по окончании ввода), ориентации потоков металла на введенный реагент. Главными недостатками таких систем являются сложность их конструкции, изготовления и обслуживания, применение низкой частоты питающего обмотки перемешивателя тока. Однако для специальных марок сталей использование таких устройств экономически оправдано, так как достигаемые показатели качества высоки и не могут быть достигнуты другим способом [5].

\section{Электромагнитные воздействия на жидкую сталь в промковше}

В промежуточном ковше производится накопление стали перед кристаллизатором МНЛ3, ее кратковременная выдержка, что способствует гомогенизации расплава по температуре, растворению или коагуляции и всплытию неметаллических включений. Кроме того, в последнее время наметилась тенденция переноса в промковш части операций внепечной обработки - в первую очередь, связанных с модифицированием, например, порошковыми проволоками. Это связано с ограниченной во времени живучестью действия модификатора в стали. В общем случае, задачи, которые необходимо решить в промковше, создать условия для дополнительного рафинирования от неметаллических включений и возможной легирующей и модифицирующей обработки, обеспечить нагрев жидкого металла и управление массовым расходом стали при разливке. Для их реализации могут быть использованы электромагнитные воздействия. 


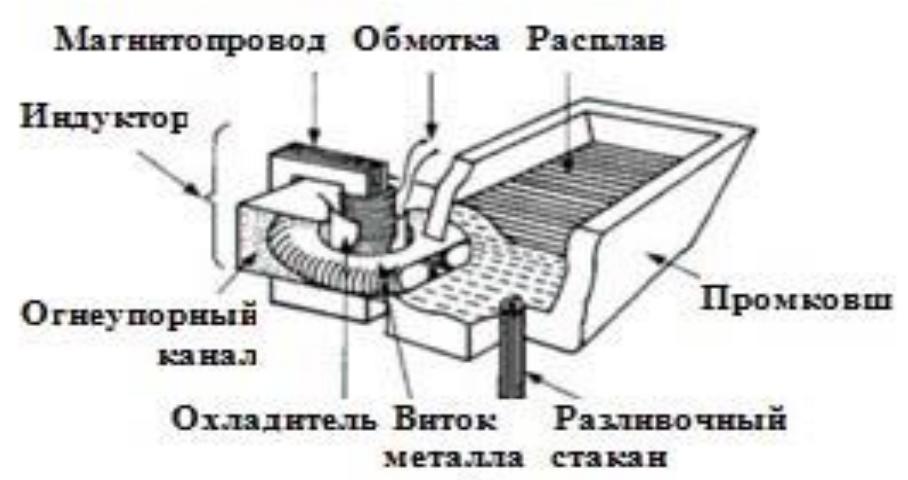

a)

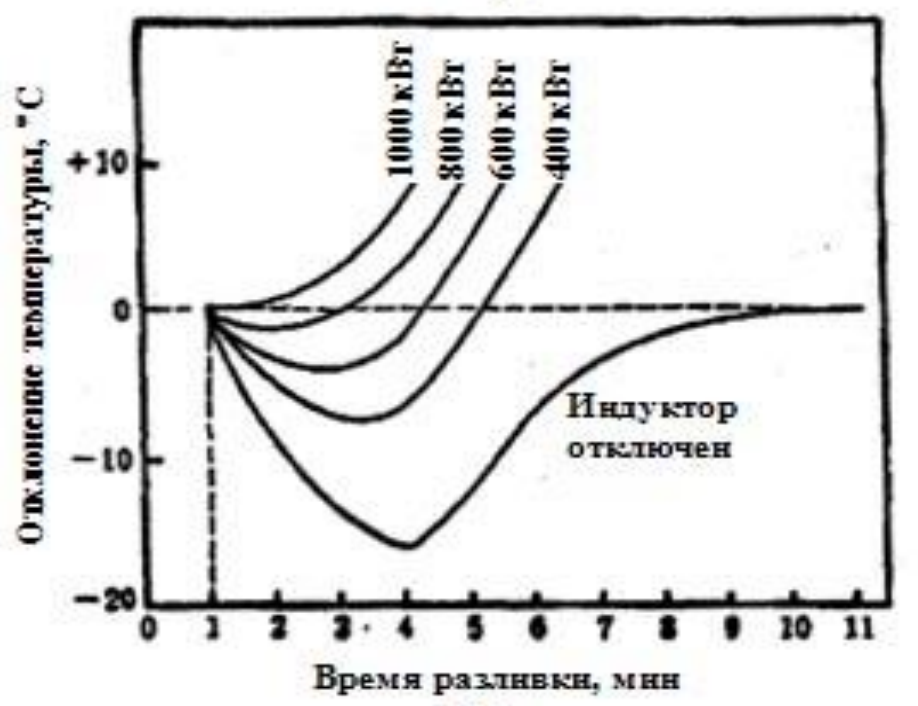

6)

Рис. 2. Индукционный промежуточный ковш Kawasaki Steel [7]: a - конструкция; б - изменение температуры стали в ковше

Как известно, электрический и термический КПД индукционных канальных устройств - самый высокий среди электрических печей и миксеров [6]. Кроме того, помимо нагрева, при индукционном способе передачи энергии, в обрабатываемом жидком металле возникают электромагнитные усилия, приводящие расплав в движение. Используя эти преимущества, компания Kawasaki Steel разработала, изготовила и провела опытно-промышленную проверку при разливке нержавеющих сталей индукционного промежуточного ковша (рис. 2) [7]. Конструктивно он представляет собой обычный промковш, к которому присоединена индукционная единица - индуктор (замкнутый магнитопровод с обмоткой) и охватывающий его огнеупорный канал, полость которого заполнена расплавом. 
Такое техническое решение обеспечило подогрев стали непосредственно перед выдачей в кристаллизатор МНЛЗ, а также позволило интенсифицировать тепломассоперенос в объеме жидкометаллической ванны. Как результат - была стабилизирована температура выдачи расплава в кристаллизатор МНЛ3 (см. рис. 3, б) и уменьшить брак, связанный с тепловым режимов разливки - улучшить качество поверхности заготовки, уменьшить в 1,5-2 раза количество трещин и в 2-3 раза - газовых и неметаллических включений, особенно в приповерхностных слоях [7].

Известны разработки по использованию электромагнитных полей для рафинирования стали в промковше. Так, предложен двухкамерный промковш с индукционным каналом [8], в котором при индуктировании сильных токов возникает периодически повторяющийся управляемый пинч-эффект - сжатие жидкометаллического проводника собственным магнитным полем, что сопровождается локальным разрежением, тепловым и силовым воздействием на расплав, и способствует удалению из него газовых и неметаллических включений.

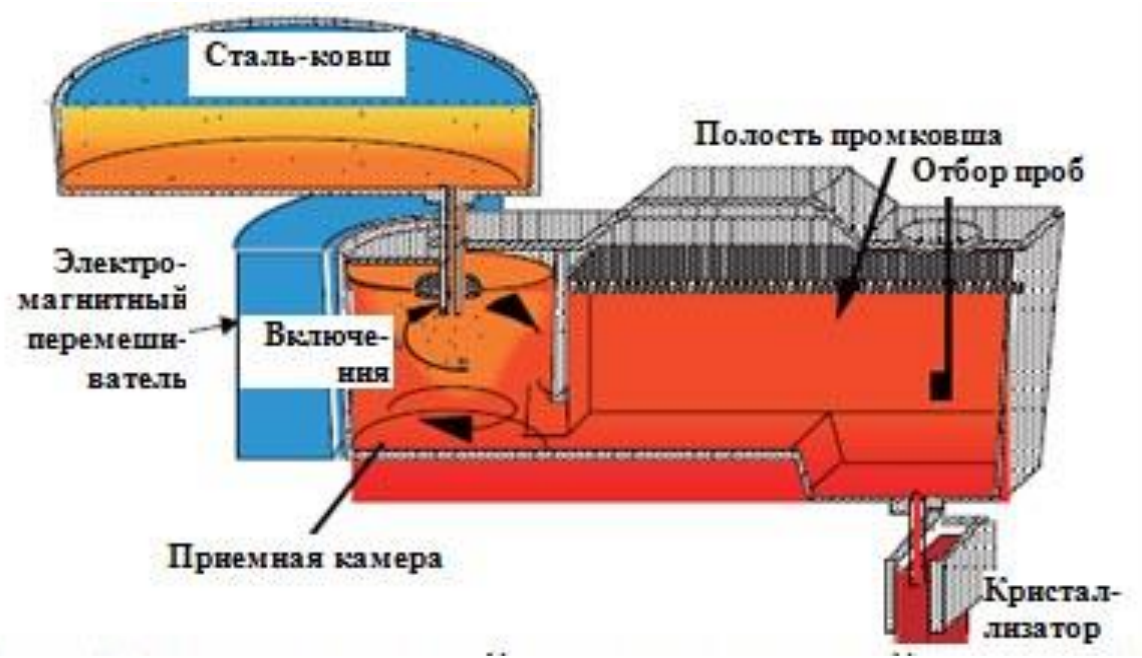

Рис. 3. Двухкамерный промежуточный ковш JFE Steel c электромагнитным перемешивателем вращающегося магнитного поля [9]

Компания JFE Steel разработала двухкамерный промежуточный ковш, в котором используется вращающееся магнитное поле (рис. 3) [9]. В промковше выделена отдельная зона приема расплава из сталь-ковша, и в ней создается 
вращательное движение жидкой стали, благодаря чему увеличивается время пребывания расплава в промковше и соответственно время для удаления неметаллических включений за счет их всплытия. Очищенный таким образом расплав подается в разливочную камеру из приемной через канал, выполненный в придонной области промковша.

\section{Применение электромагнитных воздействий на этапе формирования непрерывнолитой стальной заготовки}

После выдачи стали из промковша в кристаллизатор МНЛЗ наступает самый важный этап - формирование непрерывнолитой заготовки, которое начинает происходить непосредственно в кристаллизаторе и далее по длине МНЛЗ - в зоне вторичного охлаждения и финального затвердевания заготовки. На сегодня разработан ряд электромагнитных устройств, применяемых в перечисленных зонах для влияния на затвердевающую заготовку, и мировыми лидерами в этом направлении являются компании ABB и JFE Steel [8]. Их специалисты предлагают реализовывать концепцию полного электромагнитного перемешивания слитка и для достижения этой цели применять ряд взаимосвязанных систем, в частности (рис. 4):

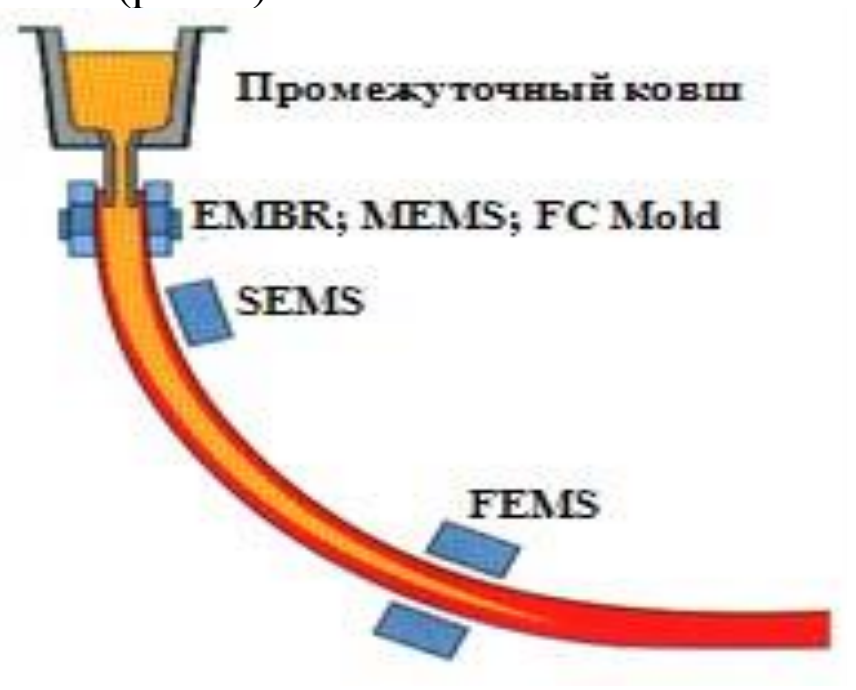

Рис. 4. Электромагнитные воздействия при формировании непрерывнолитой заготовки [8]

- устройство электромагнитного торможения потоков стали EMBR (Electromagnetic Brake), которое снижает гидродинамическое воздействие на кристаллизующуюся 
заготовку в кристаллизаторе, препятствует попаданию вглубь лунки перегретых струй стали и пузырьков инертного газа из системы защиты от вторичного окисления, а также подавляет возмущения на мениске жидкого металла;

- устройство управления движением расплава FC Mold (Flow Control Mold), также применяющегося при литье слябов и использующего поперечное магнитное поле, создаваемое многополюсными системами. FC Mold увеличивает степень снятия теплоты перегрева жидкой стали, способствует выравниванию температуры на мениске, препятствует увлечению неметаллических включений в тело заготовки;

- электромагнитного перемешивателя MEMS (Mold Electromagnetic Stirrer), выполняющего функции, аналогичные FC Mold, однако уже при литье сортовых заготовок.

- в зоне вторичного охлаждения - электромагнитный перемешиватель SEMS (Strand Electromagnetic Stirrer), который создает бегущее или вращающееся магнитное поле и может применяться при получении как слябов, так и сортовых заготовок. Цель - обеспечение перемешивания жидкой сердцевины затвердевающего слитка для воздействия на фронт кристаллизации, измельчения структуры и недопущения ликвации;

- в финальной зоне затвердевания заготовки электромагнитный перемешиватель FEMS (Final Electromagnetic Stirrer), который также является низкочастотным. Его задача обеспечить воздействие на фронт кристаллизации заготовки, препятствовать росту столбчатых кристаллов в центральной части слитка и подавлять процессы ликвации и сегрегации.

Следует упомянуть еще несколько типов электромагнитных систем, которые не нашли широкого промышленного применения, однако имеют перспективы для него. Во-первых, речь идет о так называемом «электромагнитном бустере» (Electromagnetic Booster) - устройстве, основанном на применении сверхпроводящих магнитов и токоподводящих электродов на финальной стадии кристаллизации непрерывнолитой заготовки (рис. 5) [10]. Магнитное поле и постоянный ток генерируют электромагнитную силу, в 20 раз превышающую гравитацию [10] и направленную вдоль оси слитка противоположно направлению литья. Жидкая фаза 
движется из междендритного пространства противоположно направлению литья. Образовавшиеся в отдельных местах слитка пустоты, вызванные «перехватом» жидкой лунки и являющиеся следствием неравномерности фронта кристаллизации, заполняются жидкой фазой. В результате совместного действия обжимных валков и электромагнитной силы эффект обжатия усиливается.

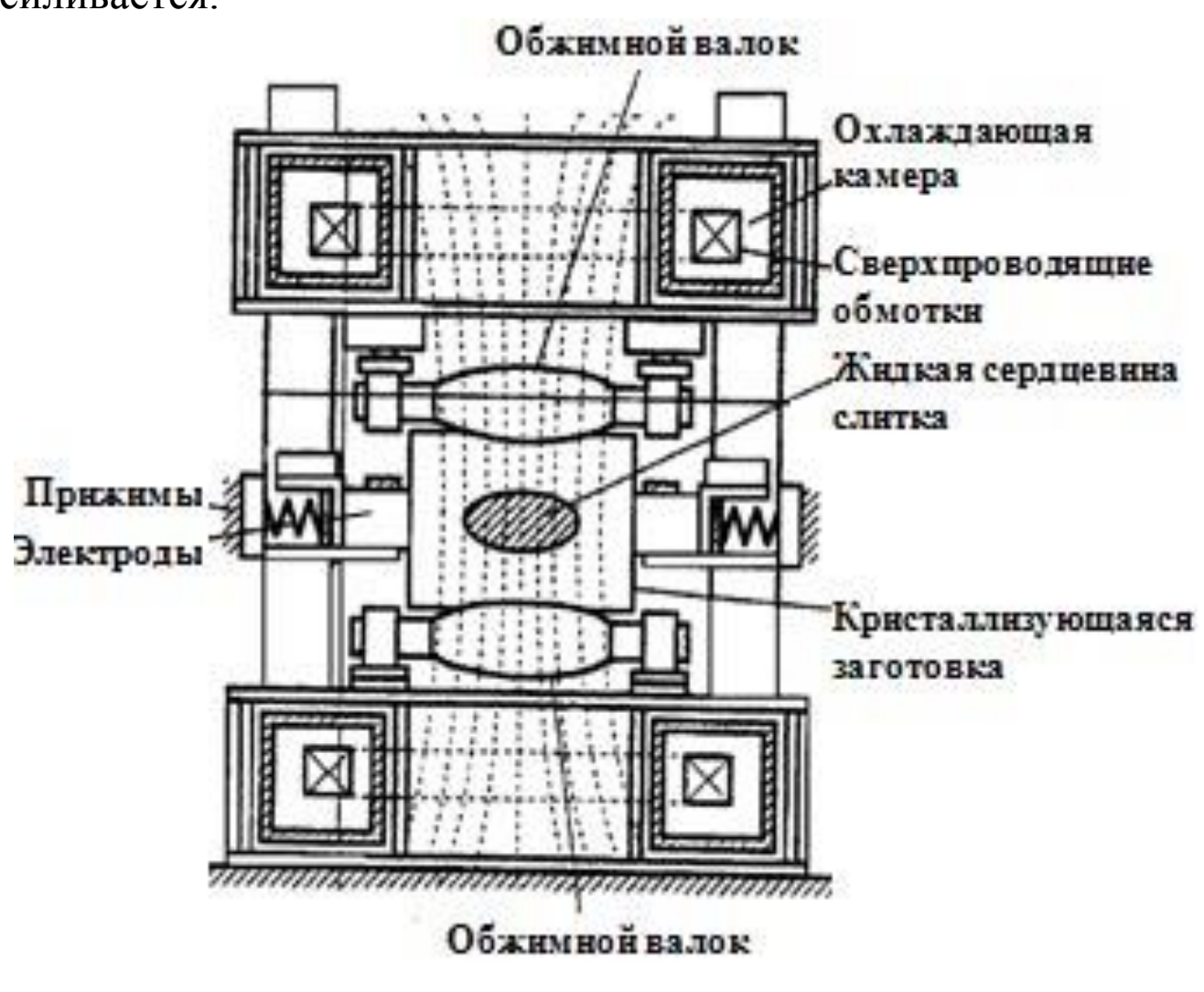

Рис. 5. Электромагнитный бустер [10]

Также известны специальные электромагнитные системы для контроля процессов непрерывной разливки $[11,12]$, в частности, электромагнитный датчик контроля попадания защитного шлака с поверхности мениска в тело заготовки, принцип действия которого основан на разности электрических свойств металлической и шлаковой среды, индукционные уровнемеры для в промковшей и кристаллизаторов МНЛЗ. Для процесса прямого получения листа путем непрерывного литья стали в двухвалковый кристаллизатор разработаны электромагнитные устройства для управления массовым расходом жидкой стали $[13,14]$, по принципу действия сходные с 
МГД-диспергаторами расплава, а также электромагнитные затворы, предотвращающие боковое истечение расплава из пространства между валками $[15,16]$.

Подытоживая вышесказанное, можно утверждать, что применение электромагнитных полей, являясь эффективным средством воздействия на металлические системы, находит все более широкое и успешное применение в технологиях непрерывной разливки стали в мире. Страны СНГ сильно отстают в сфере промышленного применения электромагнитных систем в металлургии, хотя имеют оригинальные научные и технологические разработки в этом направлении.

\section{Литература}

1. Смирнов А.Н., Пилюшенко В.Л., Минаев А.А. и др. Процессы непрерывной разливки. - Донецк: ДонНТУ, 2002. - 536 с.

2. М. Гарнье. Возможности и перспективы электромагнитной обработки материалов // Магнитная гидродинамика. - 1996. - Т. 32. - № 2. - С. 131140.

3. Открытие «Закономерность гомогенизации металлического расплава и эжектирование неметаллических включений при наложении вертикальных потоков в расплаве» / Смирнов А.Н., Пилюшенко В.Л., Дубоделов В.И. и др. // Рег. № АНО/40-09 от 12.12.2005 г. на основании Решения № 181 от 09.12.2005 г. Международной Ассоциации Авторов Научных Открытий.

4. Sh. Asai. Electromagnetic Processing of Materials - The State of the Field and Its Prospects of the International Development // Proceedings of the International Congress on Electromagnetic Processing of Materials "EMP-97". - Paris-La-Defense, France, May 27-29, 1997. - V. 1. - P. 5-12.

5. M. Эйдем. Электромагнитная индукция перемешивает жидкую сталь // Steel Times International. - Выпуск № 4 на русском языке к Международной выставке (сентябрь 1996 г.). - С. 16-17.

6. Ващенко К.И., Шумихин В.С. Плавка и внепечная обработка чугуна для отливок: Учеб. пособие. К.: Вища шк., 1992. 246 с.

7. Automatic Control of Molten Steel Temperature in Tundish and Application to Stainless Steel Casting / M. Mabuchi, Yu. Yoshii, Ts. Nozaki a. o. // Kawasaki Steel Giho. - 1985. - V. 14, No. 4. - P. 365-371.

8. Танигучи С., Бримакомб Дж. Извлечение неметаллических включений из металла силой пинча // Магнитная гидродинамика. - 1996. - № 2. - С. 158-163.

9. Yu. Miki. Applications of MHD to continuous casting of steel // The 5th International Symposium on Electromagnetic Processing of Materials "EPM 2006". - October 23-27, 2006. - Sendai, Japan. - P. 26-30. 
10. Y. Ebisu, K. Sekine. Method and apparatus for continuous casting. US Patent 6,530,418. Date of Patent: March 11, 2003.

11. K. Hanazaki, H. Miura, K. Katogi. Present monitoring technology and equipment in continuous casting mold and a future view // The 5th International Symposium on Electromagnetic Processing of Materials "EPM 2006". - October 23-27, 2006. - Sendai, Japan. - P. 94-97.

12. Sh. Fujino, Sh. Satou, Sh. Taniguchi et al. Magnetohydrodynamic calculation method for electromagnetic sensor // The 5th International Symposium on Electromagnetic Processing of Materials "EPM 2006". - October 23-27, 2006. - Sendai, Japan. - P. 759-764.

13. Zuosheng Lei, Kang Deng, Qisheng Li, Zhongming Ren, Weixuan Li, Yunbo Zhong. Physical simulation on nozzle electromagnetic brake in twin-roll strip casting // The 5th International Symposium on Electromagnetic Processing of Materials "EPM 2006". - October 23-27, 2006. - Sendai, Japan. - P. 89-93.

14. V. Bojarevics, Sh. Taniguchi, K. Pericleous. Droplet generation with modulated AC electromagnetic field at nozzle exit // The 5th International Symposium on Electromagnetic Processing of Materials "EPM 2006". October 23-27, 2006. - Sendai, Japan. - P. 259-264.

15. С.М. Хашеми, К. Швердтфегер. Электромагнитная боковая стенка при литье полосы ленточно-валковым способом // Магнитная гидродинамика. - 1996. - T. 32, № 2. - C. 177-184.

16. К.Е. Блазек, Х.Г. Гербер, И.Г. Сауседо. Использование переменных магнитных полей для бокового удержания расплава при литье полосы // Магнитная гидродинамика. - 1996. - Т. 32, № 2. - С. 185-191. 